\title{
Recent advances in the pharmacotherapy of pulmonary hypertension: practical considerations
}

\author{
Ana Lareo ${ }^{*}$, Jorge Nuche ${ }^{1,2,3^{*}}$, Maria J. Cristo Ropero1, Fernando Arribas Ynsaurriaga ${ }^{1,2}$, \\ Eduardo Oliver ${ }^{2,3}$, Pilar Escribano-Subías ${ }^{1,2}$ \\ 1 Cardiology Department, Hospital Universitario 12 de Octubre, Madrid, Spain \\ 2 Centro de Investigación Biomédica en Red de Enfermedades Cardiovasculares (CIBERCV), Instituto de Salud Carlos III, Madrid, Spain \\ 3 Centro Nacional de Investigaciones Cardiovasculares (CNIC), Madrid, Spain
}

\section{KEY WORDS}

emerging therapies, pulmonary arterial hypertension, pulmonary hypertension, pulmonary vascular remodeling, pulmonary vasodilators
Correspondence to: Pilar Escribano-Subías, MD, PhD, Cardiology Department, Hospital Universitario 12 de 0ctubre, Avenida de Córdoba $s / n$, 28041 Madrid, Spain, phone: +34913908000, email: pilar.escribano.subias@gmail.com Received: March 9, 2021 Accepted: April 2, 2021. Published online: April 5, 2021. Kardiol Pol. 2021; 79 (4): 386-392 doi:10.33963/KP.15928 Copyright by the Author(s), 2021

${ }^{*} \mathrm{AL}$ and JN contributed equally to this work.

\section{ABSTRACT}

Pulmonary arterial hypertension (PAH) is a rare disease characterized by pulmonary vascular remodeling leading to increased vascular resistance. The increased afterload contributes to the development of right ventricular dysfunction and heart failure, which is the leading cause of death among patients with PAH. The development of specific treatments has markedly improved the prognosis of this population. However, $\mathrm{PAH}$ continues to be an incurable, life-limiting condition, which creates a major burden for healthcare systems. This review describes the currently used treatments for PAH and provides insight into novel therapeutic targets that aim to reduce vascular remodeling, which ultimately leads to right ventricular failure.

Introduction Pulmonary hypertension $(\mathrm{PH})$ is characterized by increased pulmonary artery (PA) pressure with a mean pulmonary artery pressure (mPAP) of $25 \mathrm{~mm} \mathrm{Hg}$ or higher at rest. Pulmonary arterial hypertension (PAH) is defined by the presence of increased mPAP with a pulmonary capillary wedge pressure of $15 \mathrm{~mm} \mathrm{Hg}$ or lower and increased pulmonary vascular resistance (PVR) exceeding 3 Wood units. ${ }^{1,2}$

Pulmonary arterial hypertension is a complex physiopathological mechanism that affects small pulmonary vessels and leads to increased PVR. These changes are mediated by a severe endothelial dysfunction, leading to vasoconstriction and thrombosis. ${ }^{3}$ Following endothelial damage, an additional complex response with perivascular inflammation, cell proliferation, and vascular remodeling occurs. ${ }^{3}$ These vascular changes cause an increased right ventricular (RV) afterload resulting in RV remodeling and subsequent heart failure, which is the most common cause of death among patients with $\mathrm{PAH} .{ }^{4}$

The currently used therapeutic options for patients with PAH are limited to vasodilation aimed at reducing the RV afterload. Despite the continuous improvement in PAH survival, patients remain the chronically ill population at a higher risk of fatal outcomes. ${ }^{5}$ There is a need for new alternative therapies away from treating imbalance of vasoactive mediators, focused on structural remodeling of the pulmonary vasculature. ${ }^{6,7}$ The aim of this review is to summarize all novelties regarding $\mathrm{PAH}$ treatment and to identify future therapeutic targets.

Recent therapeutic weapons for pulmonary arterial hypertension Pharmacologic therapies for PAH are divided into 4 groups according to their mechanism of action ${ }^{1,8}$ (TABLE 1):

1 Calcium channel blockers are effective in patients with idiopathic and hereditary PAH who present a positive response to acute vasodilator testing. Calcium channel blockers (amlodipine, diltiazem, or nifedipine) act directly over pulmonary artery smooth muscle cells (PASMCs), avoiding the intracellular increase of $\mathrm{Ca}^{2+}$, which mainly causes vascular contraction and is also related to cell proliferation. ${ }^{9}$ Patients with PAH should be treated with high doses of calcium channel blockers and require close monitoring to confirm a sustained response. ${ }^{10}$

2 Drugs targeting the nitric oxide pathway act by inhibiting phosphodiesterase 5 (PDE5), which is mainly responsible for cyclic guanosine 
TABLE 1 Available treatments for pulmonary arterial hypertension

\begin{tabular}{|c|c|c|c|c|}
\hline \multicolumn{2}{|l|}{ Drugs } & Dosage & Adverse effects & Recommendations \\
\hline \multicolumn{5}{|c|}{ Calcium channel blockers } \\
\hline \multicolumn{2}{|l|}{ Diltiazem } & $240-720 \mathrm{mg} / 24 \mathrm{~h}$ & \multirow[t]{3}{*}{ Hypotension, edema } & \multirow{3}{*}{$\begin{array}{l}\text { IPAH, HPAH, and DPAH responding to } \\
\text { vasoreactivity testing }\end{array}$} \\
\hline \multicolumn{2}{|l|}{ Nifedipine } & $120-240 \mathrm{mg} / 24 \mathrm{~h}$ & & \\
\hline \multicolumn{2}{|l|}{ Amlodipine } & $10-20 \mathrm{mg} / 24 \mathrm{~h}$ & & \\
\hline \multicolumn{5}{|c|}{ Nitric oxide pathway } \\
\hline \multirow[t]{2}{*}{ PDE5 inhibitors } & Sildenafil & $20-80 \mathrm{mg} / 8 \mathrm{~h}$ & \multirow{2}{*}{$\begin{array}{l}\text { Headache, flushing, epistaxis, } \\
\text { priapism }\end{array}$} & \multirow{2}{*}{$\begin{array}{l}\text { Contraindicated in recent AMI, in combination } \\
\text { with nitrates, and in ischemic optic neuropathy }\end{array}$} \\
\hline & Tadalafil & $40 \mathrm{mg} / 24 \mathrm{~h}$ & & \\
\hline $\begin{array}{l}\text { Soluble guanylate } \\
\text { cyclase agonist }\end{array}$ & Riociguat & $1-2.5 \mathrm{mg} / 8 \mathrm{~h}$ & Syncope, hypotension, diarrhea & $\begin{array}{l}\text { Contraindicated in a combination therapy with } \\
\text { PDE5 inhibitors }\end{array}$ \\
\hline \multicolumn{5}{|c|}{ Endothelin receptor antagonists } \\
\hline \multicolumn{2}{|l|}{ Bosentan } & $125 \mathrm{mg} / 12 \mathrm{~h}$ & $\begin{array}{l}\text { Hepatotoxicity, diarrhea, edema, } \\
\text { teratogenic effects }\end{array}$ & $\begin{array}{l}\text { Recommended in WHO-FC class III patients with } \\
\text { Eisenmenger syndrome. Periodic liver function } \\
\text { testing should be performed. }\end{array}$ \\
\hline \multicolumn{2}{|l|}{ Ambrisentan } & $10 \mathrm{mg} / 24 \mathrm{~h}$ & $\begin{array}{l}\text { Abnormal liver function, diarrhea, } \\
\text { edema, teratogenic effects }\end{array}$ & - \\
\hline \multicolumn{2}{|l|}{ Macitentan } & $10 \mathrm{mg} / 24 \mathrm{~h}$ & $\begin{array}{l}\text { Anemia, edema, teratogenic } \\
\text { effects }\end{array}$ & $\begin{array}{l}\text { Tested in PAH associated with portal } \\
\text { hypertension. Periodic hemoglobin testing should } \\
\text { be performed. }\end{array}$ \\
\hline \multicolumn{5}{|c|}{ Inhaled prostanoids } \\
\hline \multicolumn{2}{|l|}{ Iloprost } & $\begin{array}{l}2.5-5 \mathrm{mg} \text { inhalation } \\
6-9 \text { times }\end{array}$ & $\begin{array}{l}\text { Headache, jaw pain, flushing, } \\
\text { hypotension, nausea, vomiting, } \\
\text { diarrhea }\end{array}$ & - \\
\hline \multicolumn{5}{|c|}{ Parenteral prostanoids } \\
\hline \multicolumn{2}{|l|}{ Epoprostenol } & $20-40 \mathrm{ng} / \mathrm{kg} / \mathrm{min}$ i.v. & \multirow{2}{*}{$\begin{array}{l}\text { Thrombocytopenia, headache, jaw } \\
\text { pain, flushing, hypotension, } \\
\text { nausea, vomiting, diarrhea, } \\
\text { increased risk of bleeding }\end{array}$} & \multirow{2}{*}{$\begin{array}{l}\text { Complications secondary to central catheter } \\
\text { placement or local pain. The initial dose of } \\
1-2 \mathrm{ng} / \mathrm{kg} / \mathrm{min} \text { should be titrated considering } \\
\text { adverse effects and treatment goals. }\end{array}$} \\
\hline Treprostinil & & $\begin{array}{l}20-80 \mathrm{ng} / \mathrm{kg} / \mathrm{min} \text { i.v. } \\
\text { or s.c. }\end{array}$ & & \\
\hline \multicolumn{5}{|l|}{ Oral prostanoids } \\
\hline Selexipag & & $200-1600 \mu \mathrm{g} / 12 \mathrm{~h}$ & $\begin{array}{l}\text { Headache, diarrhea, nausea, jaw } \\
\text { pain }\end{array}$ & Stable condition \\
\hline
\end{tabular}

Abbreviations: AMI, acute myocardial infarction; DPAH, drug-induced pulmonary arterial hypertension; HPAH, hereditary pulmonary arterial hypertension; IPAH, idiopathic pulmonary arterial hypertension; i.v., intravenously; PAH, pulmonary arterial hypertension; s.c., subcutaneously; PDE5, phosphodiesterase 5; WHO-FC, World Health Organization functional class

monophosphate (cGMP) hydrolysis in the lungs (sildenafil, tadalafil), ${ }^{11,12}$ or by directly stimulating soluble guanylate cyclase to generate cGMP (riociguat). ${ }^{13}$ Cyclic guanosine monophosphate causes smooth muscle cell relaxation, decreases proliferation of PASMCs, and increases apoptosis of PASMCs. Both PDE5 inhibitors and cGMP stimulators have been shown to have favorable effects on patients with $\mathrm{PAH}$, improving exercise capacity, World Health Organization functional class (WHO-FC) and hemodynamics. ${ }^{14}$ 3 Endothelial receptor antagonists (ERAs) bosentan, ambrisentan, and macitentan — block the effect of endothelin overexpression in $\mathrm{PAH}$, which leads to a potent vasoconstrictor, prothrombotic, and inflammatory response, increases exercise capacity, as well as improves hemodynamic parameters. ${ }^{15,16}$ The main limitation of this therapy is hepatic injury. Macitentan has been proven to have a better safety profile and was tested in patients with portopulmonary $\mathrm{PAH}$ with good effectiveness and safety outcomes.

4 Prostanoid analogues are arachidonic acid-derived eicosanoids that act as vasoactive mediators. These molecules, produced by the endothelium in healthy conditions, interact with their respective receptors in the PASMC membrane and provoke vascular relaxation through cyclic adenosine monophosphate production. Prostanoid analogues can be classified as follows: a. Inhaled prostanoids: Iloprost is a stable analogue of prostacyclin that causes selective pulmonary vasodilation. Added to other vasodilators, it is an effective and safe drug for patients in WHO-FC III to IV. It improves hemodynamics and exercise capacity with a lower rate of adverse effects than systemic prostanoids. ${ }^{17,18}$ Treprostinil, a prostacyclin analogue that has pulmonary vasodilator 
activity, improves WHO-FC, hemodynamics, and RV function when added to background $\mathrm{PAH}$ therapies. It is well tolerated and do not cause significant adverse effects. ${ }^{19}$

b. Parenteral prostacyclin analogues (intravenous epoprostenol or, generally subcutaneous, treprostinil) are the most potent and effective pulmonary vasodilators, which improve exercise capacity, hemodynamics, and symptoms. Despite their great effectiveness, the drugs have several adverse effects including those related to intravenous or subcutaneous infusion catheter use. ${ }^{20-22}$

Novelties of the classic New proposal for the diagnosis of pulmonary hypertension Pulmonary hypertension has been classically defined as an mPAP of $25 \mathrm{~mm} \mathrm{Hg}$ or more measured by right heart catheterization, leaving aside a subset of patients with an mPAP between 19 and $24 \mathrm{~mm} \mathrm{Hg}$ (known as borderline PH). Recently, a new threshold has been proposed (mPAP $>20 \mathrm{~mm} \mathrm{Hg}$ ), based on normal hemodynamic values of healthy individuals $(14 \pm 3.3 \mathrm{~mm} \mathrm{Hg}$ ). This change has been prompted by the risk of disease progression and poorer prognosis observed in patients with systemic sclerosis-associated PAH with an mPAP of 21 to $24 \mathrm{~mm} \mathrm{Hg} .{ }^{23}$ However, most clinical trials evaluating PAH treatments only enrolled patients with an mPAP exceeding $25 \mathrm{~mm} \mathrm{Hg}$. There was a randomized, double-blind, placebo-controlled study of patients with systemic sclerosis and $\mathrm{mPAP}$ at rest ranging between 21 and $24 \mathrm{~mm} \mathrm{Hg}$ and/ or exceeding $30 \mathrm{~mm} \mathrm{Hg}$ during exercise, which showed a possible benefit of ambrisentan (5-10 mg/d) noted with regard to hemodynamic parameter values in these patients. ${ }^{24}$ Thus, the benefits of treating patients with an mPAP below $25 \mathrm{~mm} \mathrm{Hg}$ are still to be explored.

\section{Justification for using a more aggressive approach}

The latest therapeutic recommendations advocated a more aggressive treatment from early stages with an upfront dual oral combination therapy in patients at low or intermediate risk. Furthermore, combination therapy including intravenous prostacyclin is the first-line treatment in high-risk patients. ${ }^{25}$

The AMBITION (Initial Use of Ambrisentan Plus Tadalafil in Pulmonary Arterial Hypertension) study demonstrated that combination treatment with ambrisentan and tadalafil in treatment-naïve patients reduced the risk of a composite of death, hospitalization, disease progression, or unsatisfactory long-term clinical response by $50 \%{ }^{26} \mathrm{~A}$ more aggressive approach in the TRITON (Efficacy and Safety of Initial Triple Oral Versus Initial Double Oral Combination Therapy in Patients with Newly Diagnosed Pulmonary Arterial Hypertension) trial, which compared initial dual therapy with macitentan combined with tadalafil with triple oral therapy with selexipag added, showed an improvement in PVR in both strategies and a reduction in the risk of disease progression in patients on triple therapy. ${ }^{27}$ Based on those results, currently, there is no evidence for initial triple oral therapy versus dual therapy.

Finally, the REPLACE (A Prospective, Randomized Trial of Riociguat Replacing Phosphodiesterase 5 Inhibitor Therapy in Patients with Pulmonary Arterial Hypertension Who Are Not at Treatment Goal) study tested the benefit in switching from PDE5 inhibitors to riociguat in patients at intermediate risk who did not reach treatment goals. That randomized controlled trial demonstrated that switching from PDE5 inhibitors (with or without ERAs) to riociguat resulted in a higher likelihood of clinical improvement and a reduced rate of clinical worsening and can be a strategic option for treatment escalation. ${ }^{28}$

This aggressive therapeutic algorithm is proposed for patients with classic PAH who usually have no cardiopulmonary comorbidities. Conversely, in patients with atypical $\mathrm{PAH}$, usually elderly patients with features of left heart disease or lung disease, a more conservative approach with a single drug is proposed, regardless of their risk status, in order to avoid possible adverse effects of the combined therapy. ${ }^{25}$

Oral formulations of prostanoids The main disadvantage of intravenous prostanoids is catheter-related complications such as infections or displacements. ${ }^{22}$ There are also difficulties in obtaining an adequate venous access in some patients or poor tolerance to subcutaneous infusion due to pain at the infusion site. ${ }^{20} \mathrm{On}$ the other hand, less invasive alternatives, such as inhaled iloprost, are not associated with good therapeutic adherence owing to the frequency of drug administration needed to make it effective. ${ }^{29}$ In this regard, oral systemic drugs have been developed in recent years and presented promising results in randomized clinical trials.

Selexipag is an oral selective prostacyclin receptor agonist, which can be used alone or in a combination with with ERAs or PDE5 inhibitors. It has been shown to reduce morbidity and disease progression, regardless of background treatment with ERAs, PDE5 inhibitors, or both. ${ }^{30,31}$ It is well tolerated, and its common adverse effects include headache, diarrhea, nausea, and jaw pain. After being tested in more than 500 patients with PAH, selexipag has been deemed an appropriate treatment for patients at intermediate risk.

Ralinepag, a highly selective oral prostacyclin receptor agonist with a longer half-life, has been tested in a phase 2 placebo-controlled study of patients on mono- or dual background therapy. It has demonstrated a significant improvement in $\mathrm{PVR},{ }^{32}$ but phase 3 clinical trials continue to 
recruit participants owing to delay related to the COVID-19 pandemic.

Emerging therapies in pulmonary arterial hypertension Despite a major improvement in quality of life and survival, specific treatments that aim to reduce pulmonary vascular remodeling in PAH are lacking. ${ }^{6}$ Identifying the pathobiological mechanisms underlying PAH may help to develop new drugs targeting alternative pathways that can reverse pulmonary vascular remodeling, inhibit disease progression, and improve survival. $^{7}$

The direct consequence of pulmonary vascular remodeling is obliteration of small pulmonary arterioles and vascular dysfunction. It is preceded by pulmonary endothelial dysfunction involving both the impairment of endothelium-dependent vasodilation causing vasoconstriction and reduced anticoagulant properties with increased expression of adhesion molecules and perivascular inflammation. ${ }^{3}$ The subsequent remodeling and obliteration implies intimal thickening, medial and adventitial hypertrophy due to increased proliferation and resistance to apoptosis of PASMCs, and formation of angioproliferative plexiform lesions in the last instance. ${ }^{33,34}$ Additionally, histological evidence suggests that plexiform lesions are derived from the vasa vasorum and bronchial arteries within the adventitia of pulmonary arteries and connect the systemic vasculature to pulmonary arteries and veins. ${ }^{35}$

Up to date, various drugs are being tested to specifically limit pulmonary vascular remodeling by reducing endothelial dysfunction (vasoconstriction), inflammation, thrombosis, and cell proliferation.

Drugs reducing the proliferative response Endothelial dysfunction produces an abnormal response to various growth factors such as platelet-derived growth factor (PDGF). The overexpression or activation of PDGF and PDGF receptors in the lung tissue in patients with $\mathrm{PAH}$ activates transduction pathways associated with smooth muscle hyperplasia. This mechanism mimics a neoplastic disorder with increased proliferative response and reduced apoptosis, establishing potential drug targets for $\mathrm{PAH} .{ }^{36,37}$ Imatinib, an antagonist to the PDGF receptor, was tested for the treatment of PAH in numerous studies. Although it improved exercise capacity and hemodynamics in patients with $\mathrm{PAH}$, treatment was frequently discontinued because of serious adverse events and significant adverse effects such as central nervous system hemorrhage; therefore, its use is not recommended in patients with $\mathrm{PAH} .^{38-40}$

Bone morphogenetic protein receptor 2 (BMPR2), a member of the transforming growth factor $\beta$ receptor superfamily, and protein expression are mainly observed in the endothelium in the normal pulmonary circulation. It is the main genetic factor in hereditary types of $\mathrm{PAH}$, but reduced BMPR2 protein expression is also found in patients with PAH devoid of BMPR2 mutations. ${ }^{41}$ BMPR2 protein expression is reduced in the lungs of patients with severe PAH. Abnormal BMPR2 signaling can adversely impact the endothelial barrier function, driving the transition of PA endothelial cells to smooth muscle-like mesenchymal cells, involved in vascular remodeling. ${ }^{42}$ Thus, targeting the BMPR2 pathway has emerged as a novel treatment strategy. Lungs collected from transplanted patients with idiopathic $\mathrm{PAH}$ and $\mathrm{PAH}$ associated with collagen vascular disease also showed features of marked perivascular inflammation. ${ }^{33,34}$ BMPR2 deficiency is also related to inflammatory response that prolongs $\mathrm{PH}$, suggesting the potential link between the BMPR2 pathway and inflammation. ${ }^{43}$

Sotatercept is the main novelty in PAH treatment. It blocks the tumor growth factor $\beta$ superfamily signaling pathway and could promote rebalancing of BMPR2 signaling and reverse vascular remodeling. The PULSAR (Sotatercept for the Treatment of Pulmonary Arterial Hypertension) trial is a phase 2 randomized, double-blind, placebo-controlled study assessing the efficacy and safety of subcutaneous sotatercept each 21 days (doses of $0.3 \mathrm{mg} / \mathrm{kg}$ and $0.7 \mathrm{mg} / \mathrm{kg}$ ) in adults with $\mathrm{PAH}$ receiving background therapy for PAH (including mono-, dual, and triple therapies). It demonstrated a reduction of PVR and improvement in a 6-minute walk test at both doses. Sotatercept was well tolerated and did not cause any significant adverse effects, basically erythrocytosis and thrombocytopenia. ${ }^{44}$ Multiple phase 3 trials are planned to support the use of sotatercept as a therapy in patients with $\mathrm{PAH}$.

Tacrolimus binds FK-binding protein 12, a repressor of BMP signaling, and removes it from all 3 BMPR type 1 receptors (ALK1, ALK2, and ALK3), including those preferred by BMPR2 (ALK1 and ALK3). In PA endothelial cells from patients with idiopathic PAH, low-dose FK506 reversed dysfunctional BMPR2 signaling, so it could be useful to reverse medial hypertrophy. ${ }^{45}$ A phase 2 clinical trial concluded that low-dose FK506 is safe and increases BMPR2 expression in subgroups of patients with $\mathrm{PAH}$; it also could be beneficial in treating PAH. ${ }^{46}$

Another promising drug is elafin, the endogenous human protein that plays a direct role in tumor suppression. Elafin has been reported to induce PASMC apoptosis by promoting the interaction with BMPR2 caveolin 1, which reversed vascular remodeling in experimental models of PAH. ${ }^{47,48}$ Those findings have encouraged the initiation of clinical trials to evaluate the efficacy of elafin in PAH (ClinicalTrials.gov identifier, NCT03522935).

\section{Drugs targeting metabolism and oxidative stress}

Oxidative stress is another mechanism involved in the pathogenesis and vascular remodeling in 
$\mathrm{PAH}$. In this regard, bardoxolone is an emerging promising drug. Bardoxolone methyl activates nuclear factor erythroid 2-related factor 2 , a protein that controls the expression of genes involved in protection against free radicals. Additionally, bardoxolone is an NF-kB suppressor, a proinflammatory factor related to immune response regulation. A phase 2 study on the efficacy and safety of bardoxolone in PAH has demonstrated a significant improvement in the results of the 6-minute walk test in patients with $\mathrm{PAH}$ on background oral vasodilator therapies as well as good drug tolerance. ${ }^{49}$

Metabolic dysfunction is a hallmark present in PAH-affected vessels and RV where a shift from oxidative phosphorylation to glycolysis and lactate production occurs. In this case, dichloroacetate is another promising molecule. ${ }^{50}$ Dichloroacetate was deemed useful in reversing the metabolic switch, thus re-establishing glucose oxidation, when administered in patients with idiopathic PAH. ${ }^{51}$ Nevertheless, more clinical trials are needed to further demonstrate the usefulness of this therapeutic strategy.

\section{Drugs decreasing the inflammatory response}

As mentioned before, an association between PAH with dysregulated immunity and inflammation has been established. Pulmonary vascular lesions include accumulation of inflammatory cells, mainly both macrophages and lymphocytes, but neutrophils and dendritic cells have also been described. Altered $\mathrm{T}$ regulatory cell function and changes in B-cell gene expression with an increase in interleukin 6 levels were also observed. Here, tocilizumab is a monoclonal antibody that antagonizes the interleukin 6 receptor and is under evaluation for its use in PAH. ${ }^{52}$

Accumulation of macrophages in lung arterioles is an abnormal feature of PH. Macrophages express high levels of leukotriene B4, which induces proliferation and hypertrophy of PASMCs. In relation to this, Ubenimex (bestatin) has proven to inhibit formation of the proinflammatory mediator leukotriene B4, which plays a role in inflammation in rat models of PAH. Nevertheless, the LIBERTY (A Study of Ubenimex in Patients with Pulmonary Arterial Hypertension) phase 2 study (ClinicalTrials.gov identifier, NCT02664558) failed to improve PVR or exercise capacity in patients with $\mathrm{PAH}$.

Rituximab, an anti-CD20 monoclonal antibody that selectively targets B cells, inducing their lysis, has also been tested after good results were obtained in preclinical models. However, despite the good results of rituximab in decreasing PASMC proliferation, lowering mPAP, and decreasing RV remodeling, ${ }^{53}$ few studies support its efficacy in humans. A phase 2 trial on systemic sclerosis-associated PAH will bring new evidence (ClinicalTrials.gov identifier, NCT01086540).
Interleukin 1 (IL-1) is the key player in innate immune response in $\mathrm{PAH}$ and contributes to inflammation and vascular remodeling. Interestingly, the recombinant IL-1 receptor anakinra, which inhibits both IL- $1 \alpha$ and IL-1 $\beta$, has been shown to be beneficial in patients with PAH in a pilot study. ${ }^{54}$ However, a larger, randomized, placebo-controlled trial is needed to further expand on these findings and explore the potential role of IL-1 blockade in PAH.

Drugs improving vascular function Vasoactive intestinal polypeptide (VIP) leads to relaxation of smooth muscles causing vasodilation and is deficient in patients with PAH. There is a small study with the Aviptadil (VIP) aerosol, in which it was well tolerated after a single application, but its effects on pulmonary hemodynamics and gas exchange were modest. ${ }^{55}$ Based on the results of that study, a systemic administration of VIP should be considered to obtain a greater therapeutic effect, and its subcutaneous administration is under investigation in a phase 2 study (ClinicalTrials.gov identifier, NCT03556 020).

Other vasoactive strategies, such as the use of aldosterone antagonists or angiotensin II receptor antagonists, have also been studied. However, although they are generally well tolerated, the appearance of some severe systemic adverse effects, such as hypotension, bradycardia or hypoxemia, could compromise RV function and everyday life of patients with $\mathrm{PAH}{ }^{8}$

\section{Drugs improving right ventricular function} Animal models of RV hypertrophy and failure in PAH have demonstrated downregulation of mitochondrial oxidative metabolism causing glycolysis. Ranolazine is an approved medication for the treatment of chronic stable angina, which inhibits the activation of late sodium ion channels, thus preventing calcium overload. It activates pyruvate dehydrogenase and inhibits fatty acid oxidation. In a rodent model, it successfully reversed metabolic dysfunction and improved cardiac output and exercise capacity. ${ }^{56} \mathrm{~A}$ randomized, placebo-controlled, phase Ib study showed that ranolazine is safe in patients with $\mathrm{PAH}$ who receive background $\mathrm{PAH}$ therapies, but in that study, it did not reach therapeutic levels and no effects on pulmonary hemodynamics were noted. A phase 2, randomized, double-blind, placebo-controlled multicenter study is currently testing this drug in patients with $\mathrm{PAH}$ and RV dysfunction. ${ }^{57}$ Similarly, trimetazidine has also been presented as promising therapy for $\mathrm{PAH}$, since it has the potential to activate the RV by increasing glucose oxidation, ${ }^{58}$ as evidenced by the results of the TRIMETA-PH (The Role of Trimetazidine on Right Ventricle Function in Pulmonary Arterial Hypertension) clinical trial. ${ }^{59}$

As there has been supportive evidence that $\beta$-blockers exert a favorable effect on RV 
function, it has been suggested that these drugs may be effective in PAH. Among them, carvedilol, a $\beta 1 / \beta 2$-blocker with vasodilator properties due to its ability to block the $\alpha 1$-adrenergic receptor and release nitric oxide, ${ }^{60}$ was not associated with any serious adverse events in a recent trial. ${ }^{61}$ However, larger long-term studies are required to examine the safety and efficacy of $\beta$-blockers for improving RV function in $\mathrm{PAH}$.

Conclusions Despite currently used therapeutic options and novel drugs being tested in clinical trials, PAH continues to be a disease with a poor prognosis. Due to its low prevalence, it is difficult to perform large clinical trials in order to develop new drugs that would improve prognosis. The development of new potential therapeutic options has provided some alternatives for these patients, but the mechanisms of action and optimal dosage of these drugs remain unclear. Large, randomized trials are necessary to implement these novelty therapies in our clinical practice, and treatment strategies for patients with atypical PAH and cardiopulmonary comorbidities need to be further investigated.

\section{ARTICLE INFORMATION}

\section{CONFLICT OF INTEREST None declared.}

OPEN ACCESS This is an Open Access article distributed under the terms of the Creative Commons Attribution-NonCommercial-NoDerivatives $4.0 \mathrm{In}-$ ternational License (CC BY-NC-ND 4.0), allowing third parties to download articles and share them with others, provided the original work is properly cited, not changed in any way, distributed under the same license, and used for noncommercial purposes only. For commercial use, please contact the journal office at kardiologiapolska@ptkardio.pl.

HOW TO CITE Lareo A, Nuche J, Cristo Ropero M], et al. Recent advances in the pharmacotherapy of pulmonary hypertension: practical considerations. Kardiol Pol. 2021; 79: 386-392. doi:10.33963/KP.15928

\section{REFERENCES}

1 Galiè N, Humbert M, Vachiery JL, et al. 2015 ESC/ERS Guidelines for the diagnosis and treatment of pulmonary hypertension: the Joint Task Force for the Diagnosis and Treatment of Pulmonary Hypertension of the European Society of Cardiology (ESC) and the European Respiratory Society (ERS): endorsed by: Association for European Pediatric and Congenital Cardiology (AEPC), International Society for Heart and Lung Transplantation (ISHLT). Eur Respir J. 2015; 46: 903-975.

2 Baumgartner H, De Backer J, Babu-Narayan SV, et al. 2020 ESC Guidelines for the management of adult congenital heart disease. Eur Heart J. 2021; 42: 563-645.

3 Humbert M, Guignabert C, Bonnet S, et al. Pathology and pathobiology of pulmonary hypertension: state of the art and research perspectives. Eur Respir J. 2019; 53: 1801887

4 Vonk Noordegraaf A, Chin KM, Haddad F, et al. Pathophysiology of the right ventricle and of the pulmonary circulation in pulmonary hypertension: an update. Eur Respir J. 2019; 53: 1801900.

5 Hoeper MM, Kramer T, Pan Z, et al. Mortality in pulmonary arterial hypertension: prediction by the 2015 European pulmonary hypertension quidelines risk stratification model. Eur Respir J. 2017; 50: 1700740

6 Sitbon 0, Gomberg-Maitland M, Granton J, et al. Clinical trial design and new therapies for pulmonary arterial hypertension. Eur Respir J. 2019; 53: 1801908.

7 Ghataorhe P, Rhodes C], Harbaum L, et al. Pulmonary arterial hypertension progress in understanding the disease and prioritizing strategies for drug development. J Intern Med. 2017; 282: 129-141.

8 Spaczyńska M, Rocha SF, Oliver E. Pharmacology of pulmonary arterial hypertension: an overview of current and emerging therapies. ACS Pharmacol Transl Sci. 2020; 3: 598-612.

9 Medarov BI, Judson MA. The role of calcium channel blockers for the treatment of pulmonary arterial hypertension: how much do we actually know and how could they be positioned today? Respir Med. 2015; 109: 557-564.

10 Sitbon 0 , Humbert $M_{1}$ Jaïs $X$, et al. Long-term response to calcium channel blockers in idiopathic pulmonary arterial hypertension. Circulation. 2005; 111: 3105-3111.
11 Galiè N, Ghofrani HA, Torbicki A, et al. Sildenafil citrate therapy for pulmonary arterial hypertension. N Engl J Med. 2005; 353: 2148-2157.

12 Galiè N, Brundage BH, Ghofrani HA, et al. Tadalafil therapy for pulmonary arterial hypertension. Circulation. 2009; 119: 2894-2903.

13 Ghofrani HA, Galiè N, Grimminger F, et al. Riociguat for the treatment of pulmonary arterial hypertension. N Engl J Med. 2013; 369: 330-340.

14 Archer SL, Michelakis ED. Phosphodiesterase type 5 inhibitors for pulmonary arterial hypertension. N Engl J Med. 2009; 361: 1864-1871.

15 Galiè N, Olschewski H, Oudiz RJ, et al. Ambrisentan for the treatment of pulmonary arterial hypertension: results of the Ambrisentan in Pulmonary Arterial Hypertension, Randomized, Double-Blind, Placebo-Controlled, Multicenter, Efficacy (ARIES) study 1 and 2. Circulation. 2008; 117: 3010-3019.

16 Galiè N, Rubin L, Hoeper M, et al. Treatment of patients with mildly symptomatic pulmonary arterial hypertension with bosentan (EARLY study): a double-blind, randomised controlled trial. Lancet. 2008; 371: 2093-2100.

17 Olschewski H, Simonneau G, Galiè N, et al. Inhaled iloprost for severe pulmonary hypertension. $\mathrm{N}$ Engl J Med. 2002; 347: 322-329.

18 Hoeper MM, Leuchte $H$, Halank M, et al. Combining inhaled iloprost with bosentan in patients with idiopathic pulmonary arterial hypertension. Eur Respir J. 2006; 28: 691-694.

19 Benza RL, Seeger W, McLaughlin VV, et al. Long-term effects of inhaled treprostinil in patients with pulmonary arterial hypertension: the Treprostinil Sodium Inhalation Used in the Management of Pulmonary Arterial Hypertension (TRIUMPH) study open-label extension. J Heart Lung Transplant. 2011; 30: 1327-1333.

20 Simonneau G, Barst RJ, Galie N, et al. Continuous subcutaneous infusion of treprostinil, a prostacyclin analogue, in patients with pulmonary arterial hypertension: a double-blind, randomized, placebo-controlled trial. Am J Respir Crit Care Med. 2002; 165: 800-804.

21 Rubin LJ, Mendoza J, Hood M, et al. Treatment of primary pulmonary hypertension with continuous intravenous prostacyclin (epoprostenol). Results of a randomized trial. Ann Intern Med. 1990; 112: 485-491.

22 Kitterman N, Poms A, Miller DP, et al. Bloodstream infections in patients with pulmonary arterial hypertension treated with intravenous prostanoids: insights from the REVEAL REGISTRY®. Mayo Clin Proc. 2012; 87: 825-834.

23 Coghlan JG, Wolf $M$, Distler 0 , et al. Incidence of pulmonary hypertension and determining factors in patients with systemic sclerosis. Eur Respir J. 2018; 51: 1701197.

24 Pan Z, Marra AM, Benjamin N, et al. Early treatment with ambrisentan of mildly elevated mean pulmonary arterial pressure associated with systemic sclerosis: a randomized, controlled, double-blind, parallel group study (EDITA study). Arthritis Res Ther. 2019; 21: 217.

25 Hoeper MM, Apitz C, Grunig E, et al. Targeted therapy of pulmonary arterial hypertension: updated recommendations from the Cologne Consensus Conference 2018. Int J Cardiol. 2018; 272S: 37-45.

26 Vachiéry JL, Galiè N, Barberá JA, et al. Initial combination therapy with ambrisentan + tadalafil on pulmonary arterial hypertension-related hospitalization in the AMBITION trial. J Heart Lung Transplant. 2019; 38: 194-202.

27 Chin KM, Sitbon 0, Doelberg M, et al. Efficacy and safety of initial triple ora versus initial double oral combination therapy in patients with newly diagnosed pulmonary arterial hypertension (PAH): results of the randomized controlled TRITON study. Am J Respir Crit Care Med. 2020; 201: A2928.

28 Hoeper MM, Ghofrani H-A, Benza RL, et al. REPLACE: a prospective, randomized trial of riociguat replacing phosphodiesterase 5 inhibitor therapy in patients with pulmonary arterial hypertension who are not at treatment goal. Eur Respir J. 2017; 50: PA2417.

29 Del Pozo R, Blanco I, Hernández-González I, et al. Real-life experience of inhaled iloprost for patients with pulmonary arterial hypertension: Insights from the Spanish REHAP registry. Int J Cardiol. 2019; 275: 158-164.

30 Simonneau G, Torbicki A, Hoeper MM, et al. Selexipag: an oral, selective prostacyclin receptor agonist for the treatment of pulmonary arterial hypertension. Eur Respir J. 2012; 40: 874-880.

31 Sitbon 0, Channick R, Chin KM, et al. Selexipag for the treatment of pulmonary arterial hypertension. N Engl J Med. 2015; 373: 2522-2533.

32 Torres F, Farber H, Ristic A, et al. Efficacy and safety of ralinepag, a novel oral IP agonist, in PAH patients on mono or dual background therapy: results from a phase 2 randomised, parallel group, placebo-controlled trial. Eur Respir J. 2019; 54: 1901030.

33 Stacher E, Graham BB, Hunt JM, et al. Modern age pathology of pulmonary arterial hypertension. Am J Respir Crit Care Med. 2012; 186: 261-272.

34 Thompson AAR, Lawrie A. Targeting vascular remodeling to treat pulmonary arterial hypertension. Trends Mol Med. 2017; 23: 31-45.

35 Galambos C, Sims-Lucas S, Abman SH, Cool CD. Intrapulmonary bronchopulmonary anastomoses and plexiform lesions in idiopathic pulmonary arterial hypertension. Am J Respir Crit Care Med. 2016; 193: 574-576.

36 Pullamsetti SS, Savai R, Seeger W, Goncharova EA. Translational advances in the field of pulmonary hypertension. From cancer biology to new pulmonary arterial hypertension therapeutics. Targeting cell growth and proliferation signaling hubs. Am J Respir Crit Care Med. 2017; 195: 425-437. 
37 Boucherat 0 , Vitry G, Trinh I, et al. The cancer theory of pulmonary arterial hypertension. Pulm Circ. 2017; 7: 285-299.

38 Ghofrani HA, Seeger W, Grimminger F. Imatinib for the treatment of pulmonary arterial hypertension. N Engl J Med. 2005; 353: 1412-1413.

39 Ghofrani HA, Morrell NW, Hoeper MM, et al. Imatinib in pulmonary arterial hypertension patients with inadequate response to established therapy. Am J Respir Crit Care Med. 2010; 182: 1171-1177.

40 Frost AE, Barst RJ, Hoeper MM, et al. Long-term safety and efficacy of imatinib in pulmonary arterial hypertension. J Heart Lung Transplant. 2015; 34: 1366-1375.

41 Atkinson C, Stewart S, Upton PD, et al. Primary pulmonary hypertension is associated with reduced pulmonary vascular expression of type II bone morphogenetic protein receptor. Circulation. 2002; 105: 1672-1678.

42 Ranchoux B, Antigny F, Rucker-Martin C, et al. Endothelial-to-mesenchymal transition in pulmonary hypertension. Circulation. 2015; 131: 1006-1018.

43 Soon E, Crosby A, Southwood M, et al. Bone morphogenetic protein receptor type II deficiency and increased inflammatory cytokine production. A gateway to pulmonary arterial hypertension. Am J Respir Crit Care Med. 2015; 192: 859-872.

44 Badesch D, Gibbs S, Gomberg-Maitland M, et al. PUISAR: a phase 2, randomized, double-blind, placebo-controlled study to assess the efficacy and safety of sotatercept (ACE-011) when added to standard of care (SOC) for treatment of pulmonary arterial hypertension (PAH). Eur Respir J. 2019; 54: PA4750.

45 Spiekerkoetter E, Tian X, Cai J, et al. FK506 activates BMPR2, rescues endothelial dysfunction, and reverses pulmonary hypertension. J Clin Invest. 2013; 123: 3600-3613.

46 Spiekerkoetter E, Sung YK, Sudheendra D, et al. Randomised placebo-controlled safety and tolerability trial of FK506 (tacrolimus) for pulmonary arterial hypertension. Eur Respir J. 2017; 50: 1602449.

47 Nickel NP, Spiekerkoetter E, Gu M, et al. Elafin reverses pulmonary hypertension via caveolin-1-dependent bone morphogenetic protein signaling. Am J Respir Crit Care Med. 2015; 191: 1273-1286.

48 Shaw $L$, Wiedow 0 . Therapeutic potential of human elafin. Biochem Soc Trans. 2011; 39: 1450-1454.

49 Oudiz R, Meyer C, Chin M, et al. Initial data report from "LARIAT": a phase 2 study of bardoxolone methyl in PAH patients on stable background therapy. Chest. 2015; 148: 639A-639A

50 Li B, Yan J, Shen Y, et al. Dichloroacetate prevents but not reverses the formation of neointimal lesions in a rat model of severe pulmonary arterial hypertension. Mol Med Rep. 2014; 10: 2144-2152. Michelakis ED, Gurtu V, Webster L, et al. Inhibition of pyruvate dehydrogenase kinase improves pulmonary arterial hypertension in genetically susceptible patients. Sci TransI Med. 2017; 9: eaa04583.

51 Hernández-Sánchez J, Harlow L, Church C, et al. Clinical trial protocol for TRANSFORM-UK: a therapeutic open-label study of tocilizumab in the treatment of pulmonary arterial hypertension. Pulm Circ. 2018; 8: 1-8.

52 van Hout GP, Bosch L, Ellenbroek GH, et al. The selective NLRP3-inflammasome inhibitor MCC950 reduces infarct size and preserves cardiac function in a pig model of myocardial infarction. Eur Heart J. 2017; 38: 828-836.

53 Trankle CR, Canada JM, Kadariya D, et al. IL-1 blockade reduces inflammation in pulmonary arterial hypertension and right ventricular failure: a single-arm, open-label, phase IB/II pilot study. Am J Respir Crit Care Med. 2019; 199: 381-384.

54 Leuchte HH, Baezner C, Baumgartner RA, et al. Inhalation of vasoactive intestinal peptide in pulmonary hypertension. Eur Respir J. 2008; 32: 1289-1294.

55 Piao L, Fang YH, Cadete V], et al. The inhibition of pyruvate dehydrogenase kinase improves impaired cardiac function and electrical remodeling in two models of right ventricular hypertrophy: resuscitating the hibernating right ventricle. J Mol Med (Berl). 2010; 88: 47-60.

56 Han Y, Forfia PR, Vaidya A, et al. Rationale and design of the ranolazine PH-RV study: a multicentred randomised and placebo-controlled study of ranolazine to improve RV function in patients with non-group 2 pulmonary hypertension. Open Heart. 2018; 5: e000736.

57 Fang YH, Piao L, Hong Z, et al. Therapeutic inhibition of fatty acid oxidation in right ventricular hypertrophy: exploiting Randle's cycle. J Mol Med (Berl). 2012; 90: 31-43.

58 Sakti Muliawan H, Widyantoro B, Soerarso R, et al. P194 Trimetazidine preserves right ventricular function on pulmonary arterial hypertension patients in national cardiovascular center harapan kita hospital Indonesia. Eur Heart J. 2020; 41 (suppl 1): ehz872.068.

59 Oliver E, Mayor F, D'Ocon P. Beta-blockers: historical perspective and mechanisms of action. Rev Esp Cardiol (Engl Ed). 2019; 72: 853-862.

60 Farha S, Saygin D, Park MM, et al. Pulmonary arterial hypertension treatment with carvedilol for heart failure: a randomized controlled trial. JCI Insight. 2017; 2: e95240. 